DE

M E D I C I N A

T R O P I C A L

$\mathrm{DE}$

S ÃO PAULO

JOURNAL OF THE SÃO PAULO INSTITUTE OF TROPICAL MEDICINE

1 Universidade Federal de Pernambuco,

Recife, Pernambuco, Brazil

${ }^{2}$ Fundação Oswaldo Cruz, Instituto Aggeu Magalhães, Departamento de Imunologia, Recife, Pernambuco, Brazi

${ }^{3}$ Fundação de Hematologia e Hemoterapia de Pernambuco, Recife, Pernambuco, Brazil

${ }^{4}$ Universidade Federal do Grande Dourados, Faculdade de Ciências da Saúde, Dourados, Mato Grosso do Sul, Brazil

Correspondence to: Manoel Sebastião da Costa Lima Junior

Fundação Oswaldo Cruz, Instituto Aggeu Magalhães, Departamento de Imunologia, Avenida Professor Moraes Rego, CEP 50670-420, Recife, PE, Brazil

E-mail: manoel.lima@cpqam.fiocruz.br

Received: 16 August 2020

Accepted: 7 September 2020

\section{Asymptomatic Leishmania infection in blood donors from a major blood bank in Northeastern Brazil: a cross-sectional study}

\author{
Lucas Portela Silva', Silvia Montenegro², Roberto Werkauser², Kamila \\ Gaudêncio da Silva Sales², Fábia Carla Silva Soares ${ }^{2}$, Vlaudia Maria Assis \\ Costa $^{1}$, Ana Cristina Bezerra ${ }^{3}$, Maria Betania do Amaral Pinto ${ }^{3}$, Suzany Maria \\ Ferreira $^{3}$, Herintha Coeto Neitzke-Abreu${ }^{4}$, Filipe Dantas-Torres ${ }^{2}$, Manoel \\ Sebastião da Costa Lima Junior ${ }^{\left({ }^{\circ}\right.} 2$
}

\section{ABSTRACT}

This study has estimated the risk of Leishmania transmission via blood transfusion in one of the largest blood banks in Northeastern Brazil, where visceral leishmaniasis is endemic. Five hundred blood samples from donors were tested for circulating Leishmania spp. DNA by real-time PCR. Positive samples were tested by a species-specific conventional PCR targeting Leishmania infantum. Overall, 6.2\% (95\% CI: 4.1-8.3\%) of the samples carried Leishmania DNA and in one sample the species was confirmed as L. infantum. No statistically significant differences were found in relation to gender, sex, education level, incomeas well as the place of residence between positive and negative blood donors. Our results confirm the presence of asymptomatic Leishmania carriers among blood donors in a large blood bank in Northeastern Brazil. Considering the studied population, we estimate that for every 1,000 blood donors screened, 41 to 83 will be positive for Leishmania DNA. This finding reinforces the urgent need for elaborating specific Blood bank guidelines to allow the early detection of asymptomatic Leishmania carriers among blood donors before their blood products are transfused to uninfected individuals.

KEYWORDS: Blood donors. Leishmania. Asymptomatic infection. Blood bank. Surveillance.

\section{INTRODUCTION}

Visceral leishmaniasis (VL) is a severe neglected disease caused by protozoa belonging to the Leishmania donovani species complex, which affects approximately 200,000 to 400,000 people annually, with most of the cases being reported in Brazil, India, Sudan, South Sudan, Ethiopia and Bangladesh ${ }^{1}$. The clinical manifestations of $\mathrm{VL}$ are directly related to the patient's immune response and also to virulence factors of the infecting Leishmania species². Hence, even though many infected people remain asymptomatic, the disease is often severe and potentially fatal ${ }^{3,4}$. Indeed, it is estimated that 20,000 to 40,000 people die from VL every year in endemic areas ${ }^{1}$.

In the Mediterranean Basin, Middle East, Central Asia, South America and Central America, VL is a zoonosis caused by Leishmania infantum ${ }^{5}$. Although primarily transmitted by female phlebotomine sand flies ${ }^{6}, L$. infantum may also be transmitted by other routes, including blood transfusion ${ }^{7}$. Cases of transfusiontransmitted leishmaniasis have been reported in several countries such as Belgium, 
France, Brazil, Sweden and the United Kingdom ${ }^{7}$. In spite of that, blood donors' screening for $L$. infantum infection is not routinely performed in several endemic countries ${ }^{7,8}$, including $\mathrm{Brazil}^{9}$. Although the risk of $L$. infantum transmission via blood transfusion is eminent, it remains largely underestimated in most countries. A screening in blood banks of different Brazilian cities (Montes Claros, Fortaleza, and Teresina) reported that among 615 clinically eligible donors, seven $(1.1 \%)$ were positive in the screening procedure, a rapid immunochromatographic test ${ }^{10}$. Considering the total of 608 eligible donors, 37 (6.1\%) were positive to Leshmania spp. by a commercial ELISA. Furthermore, among 296 patients who were transfused with red blood cells or platelet concentrates from the above-mentioned donors, $23(7.8 \%)$ were seropositive prior to blood transfusion and $13(4.4 \%)$ received blood from positive donors. Six patients were followed-up and two of these six seroconverted between 60 and 90 days after blood transfusion ${ }^{10}$. This study illustrates the tip of the iceberg regarding $L$. infantum transmission by blood donors in Brazil.
Evidence accumulated in recent decades indicates that many individuals infected with Leishmania living in endemic areas may remain asymptomatic and become blood donors. Nonetheless, the risk of Leishmania transmission via blood transfusion remains largely underestimated. In this context, the aim of the present study was to estimate the risk of Leishmania transmission via blood transfusion in one of the largest blood banks in Northeastern Brazil, where $\mathrm{VL}$ is endemic.

\section{METHODS}

\section{Study population}

This cross-sectional study was carried out in the Fundacao de Hematologia e Hemoterapia de Pernambuco (Hemope), from August to September of 2017 (Figure 1). Before blood collection, blood donors were invited to participate in the study. After signing the informed consent, blood donors answered a questionnaire regarding age, schooling, income and place of residence. Routinely, all
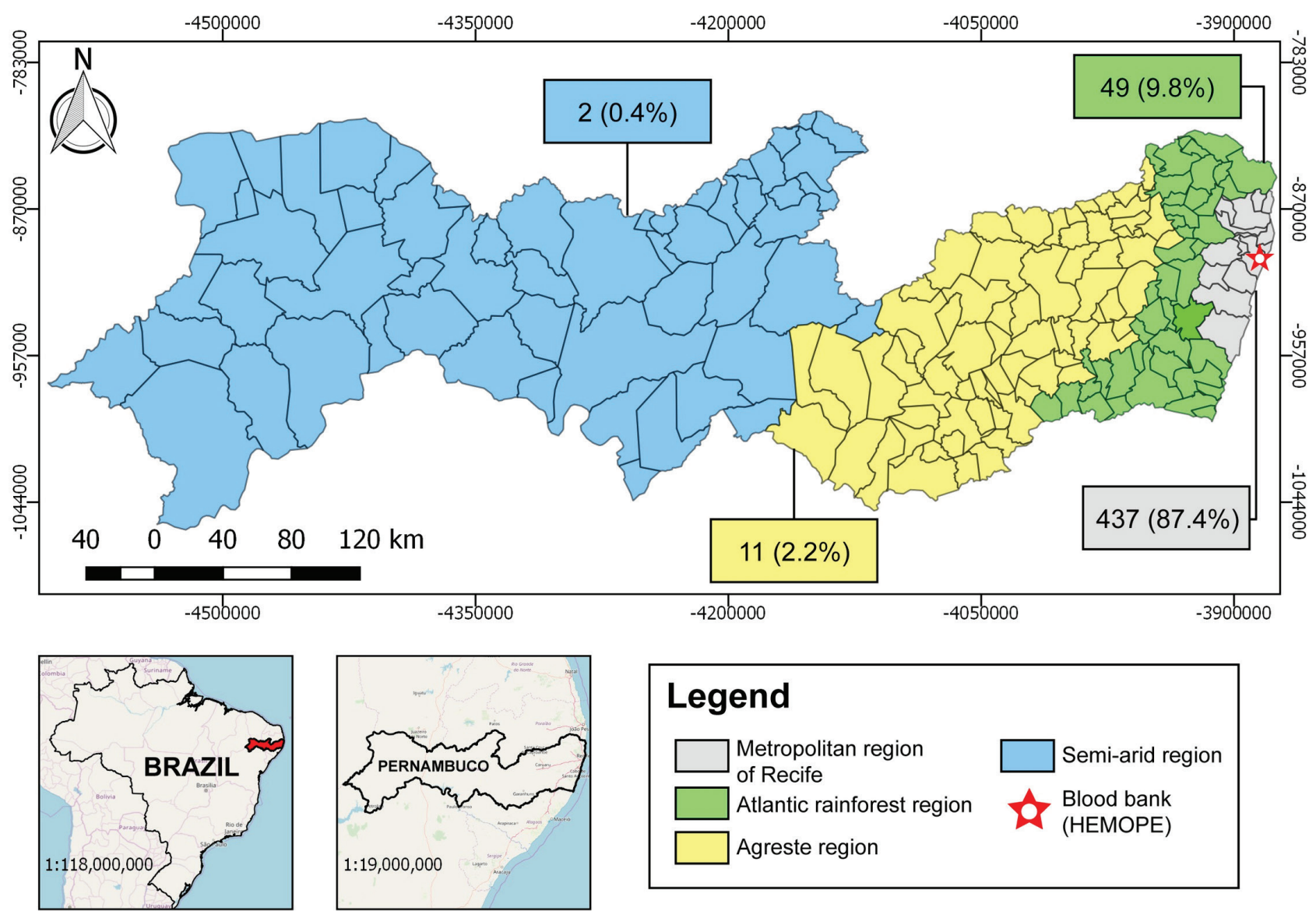

\section{Legend}

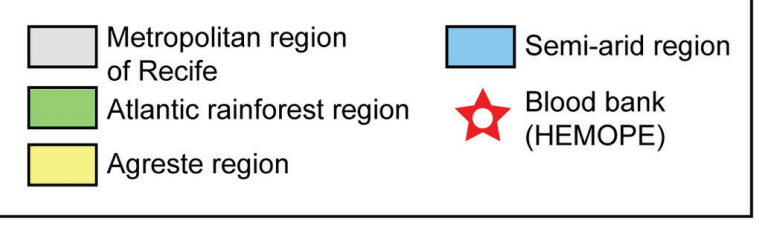

Figure 1 - Location of the Fundacao de Hematologia e Hemoterapia de Pernambuco (Hemope) and the geographic regions of Pernambuco State, from where blood donors came from. Numbers and percentages (in parentheses) refer to the number of positive patients and the positivity in each region. The maps were produced using the QGIS software version 2.18.28 (Free Software Foundation, Boston, Massachusetts, USA) and based on public geographical data obtained from OpenStreetMaps ${ }^{30}$. 
blood donors are subjected to a clinical screening (i.e., heart rate, blood pressure, temperature, weight, height, hemoglobin and hematocrit levels) and only those classified as clinically healthy (asymptomatic) are considered eligible for donation. In this blood bank, blood samples from donors are also routinely screened for syphilis, Chagas disease, hepatitis B and C, human immunodeficiency virus (HIV), human T-lymphotropic virus (HTLV) I and II, in addition to blood typing and $\mathrm{Rh}$ factor.

This study was approved by the ethics and research committees of the Aggeu Magalhaes Institute (Fiocruz-PE) (CAEE No 65770317.9.0000.5190) and the Hematology and Hemotherapy Foundation of Pernambuco (Hemope). All subjects were adults and voluntarily signed an informed consent before their enrolment in the study. All procedures were carried out in accordance with relevant guidelines and regulations.

\section{Sampling}

Venous blood samples (approximately $4 \mathrm{~mL}$ ) were withdrawn from 500 blood donors and immediately placed into EDTA tubes (BD Vacutainer, Becton Dickinson, Franklin Lakes, NJ, USA), which were previously labelled with a unique bar code for each donor. Then, $600 \mu \mathrm{L}$ aliquots were transferred to a $1.5 \mathrm{~mL}$ microtube (Eppendorf, Hamburg, Germany) and frozen at $-80{ }^{\circ} \mathrm{C}$ until further analysis.

\section{Molecular diagnosis}

Extraction of genomic DNA from blood samples and from cultured Leishmania promastigotes [reference strains: L. infantum (MHOM/BR/2016/DBA) and Leishmania braziliensis (MHOM/BR/2016/FAL)] were performed using the Wizard Genomic DNA Purification kit (Promega Corporation, Madison, WI, USA) according to the manufacturer's instructions. The quality of the extracted DNA was assessed using a NanoDrop-2000C spectrophotometer (Thermo Scientific, Waltham, MA, USA).

DNA samples were screened for the presence of Leishmania spp. kinetoplast DNA by a realtime PCR (qPCR), using the primers LEISH-1 (5'-AACTTTTCTGGTCCTCCGG GTAG-3') and LEISH-2 (5'-ACCCCCAGTTTCCCGCC-3'), and the TaqMan-MGB probe (FAM-5' -AAAAATGGGTGCAGAAAT-3' '-nonfluorescent quencher-MGB), as described elsewhere ${ }^{11}$. This assay detects different Leishmania spp., not only L. infantum ${ }^{12}$. The reaction mixture contained $7.5 \mu \mathrm{L}$ of TaqMan Genotyping master mix (2X), $1.35 \mu \mathrm{L}$ of each primer (final concentration of $900 \mathrm{nM}$ each), $0.3 \mu \mathrm{L}$ of probe (final concentration of $200 \mathrm{nM}$ each), $2.5 \mu \mathrm{L}$ of sterile water (DNase and RNase free) and $2.0 \mu \mathrm{L}$ of genomic DNA, in a final volume of $15 \mu \mathrm{L}$. The thermal cycling conditions (QuantStudio 5 Real-Time PCR machine, Applied Biosystems, Foster City, CA, USA) were set as follow: $50^{\circ} \mathrm{C}$ for $2 \mathrm{~min}, 95^{\circ} \mathrm{C}$ for $10 \mathrm{~min}, 40$ cycles of $95^{\circ} \mathrm{C}$ for $15 \mathrm{~s}$, and $60{ }^{\circ} \mathrm{C}$ for $1 \mathrm{~min}$. Samples were initially screened one by one and them positive samples were rested in duplicate. A standard curve with six serial dilutions $(100 \mathrm{pg}, 10 \mathrm{pg}, 1 \mathrm{pg}$, $100 \mathrm{fg}, 10 \mathrm{fg}$, and $1 \mathrm{fg}$ per reaction) of genomic DNA from L. infantum was used as positive controls and also to estimate the parasite load in blood samples. DNA-free water was used as non-template control (NTC).

Positive samples by qPCR were further tested by a species-specific conventional PCR assay, using the primers FLC2 (5'-GTCAGTGTCGGAAACTAATCC GC-3') and RLC2 (5'-GGGAAATTGGCCTCCCTGAG-3'), which amplify a $230 \mathrm{bp}$ fragment of $L$. infantum $\mathrm{kDNA}^{13}$. The final reaction volume was $25 \mu \mathrm{L}$, consisting of $1 \mathrm{X}$ buffer, $0.2 \mathrm{mM}$ dNTP (dATP, dCTP, dGTP, and dTTP), $1.5 \mathrm{mM} \mathrm{MgCl}, 1.5 \mathrm{U}$ Taq Polymerase (Invitrogen, Thermo Scientific, Waltham, MA, USA), 0.4 pmol of each primer and $2 \mu \mathrm{L}$ of genomic DNA. Genomic DNA from $L$. infantum and $L$. braziliensis were used as positive and negative controls, respectively. PCR assays were carried out in a LifeECO Thermal Clycler Bioer (Bioer Technology, Hangzhou, China), using the following thermal cycling conditions: initial denaturation at $95^{\circ} \mathrm{C}$ for $10 \mathrm{~min}$, followed by 35 cycles of $94{ }^{\circ} \mathrm{C}$ for $1 \mathrm{~min}, 56^{\circ} \mathrm{C}$ for $1 \mathrm{~min}$ and $72{ }^{\circ} \mathrm{C}$ for $30 \mathrm{~s}$, and a final extension at $72{ }^{\circ} \mathrm{C}$ for $10 \mathrm{~min}$. PCR products were subjected to $1 \%$ agarose gel electrophoresis with $1 \mathrm{X}$ tris-borate-EDTA buffer ( $\mathrm{pH} \mathrm{8.0)}$ at $150 \mathrm{~V}$ and $400 \mathrm{~mA}$ for $1 \mathrm{~h}$ and $20 \mathrm{~min}$. Gels were stained with ethidium bromide $(0.5 \mu \mathrm{g} / \mathrm{mL})$ and visualized under ultraviolet light.

\section{Statistical analyses}

The minimum sample size $(n=377)$ was calculated considering a 5\% margin of error, $95 \%$ confidence level, unknown population size and expected positivity of 50\%, using GraphPad Prism software version 5.0 (GraphPad Software Inc., San Diego, CA, USA). The positivity rate was calculated as the percentage (\%) of positive individuals among all screened individuals. The $95 \%$ confidence interval was also calculated. The positivity rate was analyzed according to sociodemographic characteristics of the study population, using Chi-square $\left(\chi^{2}\right)$ or G-test $(G)$. Differences were considered statistically significant when the $P$ value was equal or less than 5. Statistical analyses were conducted using the BioEstat software, version 5.3 (Mamirauá Institute, Tefé, Amazonas, Brazil). 


\section{RESULTS}

Among the total of 500 blood donors enrolled in this study, $42.6 \%(n=213)$ were female and $57.4 \%(n=287)$ male (Table 1). Regarding the skin color, $35.0 \%$ (175) were of mixed ethnicity, 30.4\% $(n=152)$ white, $25.4 \%(n=127)$ black, with other self-declared skin colors accounting for the remaining $9.2 \%(n=46)$. Regarding age, $50.2 \%(n=251)$ of the donors were $18-25$ years old, $27.4 \%(n=137)$
26-33 years old, $12.2 \%(n=61) 34-41$ years old, $8.2 \%$ $(n=41) 42-50$ years old and $2.0 \%(n=10) 51-60$ years old. The age groups 18-25 and 26-33 years old corresponded to $77.6 \%$ of the total. In respect to the education level, most donors had completed superior education $(n=479 ; 95.8 \%)$, with $4.2 \%$ ( $n=21)$ of the donors presenting with only the elementary education.

Analyzing the place of residence, $437(87.4 \%)$ resided in the metropolitan region of Recife, 49 (9.8\%) in the Atlantic

Table 1 - Sociodemographic characteristics of blood donors in relation to their positivity to Leishmania DNA by real-time PCR, Recife, Brazil.

\begin{tabular}{|c|c|c|c|}
\hline Variables & $\begin{array}{c}\text { Leishmania DNA-negative } \\
n(\%)\end{array}$ & $\begin{array}{l}\text { Leishmania DNA-positive } \\
\qquad n(\%)\end{array}$ & Statistics \\
\hline \multicolumn{4}{|l|}{ Gender } \\
\hline Female & $199(93.4)$ & $14(6.6)$ & $\chi^{2}=0.06, d f=1, P=0.812$ \\
\hline Male & $270(94.1)$ & $17(6.0)$ & \\
\hline \multicolumn{4}{|l|}{ Skin color } \\
\hline White & $142(93.4)$ & $10(6.6)$ & $G=2.41, d f=4, P=0.661$ \\
\hline Black & $117(92.1)$ & $10(7.9)$ & \\
\hline Yellow & $44(97.8)$ & $1(2.2)$ & \\
\hline Mixed Ethnicity & $165(94.3)$ & $10(5.7)$ & \\
\hline Indigenous & $1(100.0)$ & $0(0.0)$ & \\
\hline \multicolumn{4}{|l|}{ Age (years) } \\
\hline $18-25$ & $234(93.2)$ & $17(6.8)$ & $G=2.60, d f=4, P=0.626$ \\
\hline $26-33$ & $128(93.4)$ & $9(6.6)$ & \\
\hline $34-41$ & $59(96.7)$ & $2(3.3)$ & \\
\hline $42-50$ & $38(92.7)$ & $3(7.3)$ & \\
\hline $51-60$ & $10(100.0)$ & $0(0.0)$ & \\
\hline \multicolumn{4}{|l|}{ Schooling } \\
\hline $1-5$ years & $5(100.0)$ & $0(0.0)$ & $G=6.49, d f=3, P=0.090$ \\
\hline $6-9$ years & $16(100.0)$ & $0(0.0)$ & \\
\hline High school & $239(95.6)$ & $11(4.4)$ & \\
\hline Higher education & $209(91.3)$ & $20(8.7)$ & \\
\hline \multicolumn{4}{|l|}{ Income* } \\
\hline$<1$ minimum wage & $6(100.0)$ & $0(0.0)$ & $G=3.43, d f=4, P=0.488$ \\
\hline 1-2 minimum wages & $251(94.0)$ & $16(6.0)$ & \\
\hline 3-4 minimum wages & $127(91.4)$ & $12(8.6)$ & \\
\hline 5-6 minimum wages & $48(96.0)$ & $2(4.0)$ & \\
\hline$\geq 7$ minimum wages & $35(97.2)$ & $1(2.8)$ & \\
\hline \multicolumn{4}{|l|}{ Place of residence } \\
\hline Metropolitan region of Recife & $408(93.4)$ & $29(6.6)$ & $G=2.36, d f=4, P=0.670$ \\
\hline Atlantic rainforest & $47(95.9)$ & $2(4.1)$ & \\
\hline Agreste region & $11(100.0)$ & $0(0.0)$ & \\
\hline Semi-arid region & $2(100.0)$ & $0(0.0)$ & \\
\hline Other State & $1(100.0)$ & $0(0.0)$ & \\
\hline
\end{tabular}

${ }^{*}$ In the income variable, two participants did not respond. G-test $=G$; degrees of freedom $=d f$ 
rainforest region, $11(2.2 \%)$ in the agreste region, two $(0.4 \%)$ in the semi-arid region, one $(0.2 \%)$ in another state.

When asked about the water supply, $99.6 \%$ (498) of the donors reported access to potable water. Regarding the type of sewage system, $87.2 \%(n=436)$ reported having access to basic sanitation, $5.2 \%(n=26)$ had no access and $7.6 \%$ $(n=38)$ did not know.

Upon qPCR testing, 31 out of 500 (6.2\%; 95\% CI: 4.1-8.3\%) blood samples were found to carry Leishmania DNA. Most positive donors were males and individuals with age ranging from 18 to 25 years (Table 1). Almost all Leishmania-positive donors were residents of the Metropolitan region of Recife $(n=29)$, with only two donors coming from the agreste region. The parasite load ranged from 2.2 to 201.0 parasites per $\mathrm{mL}$ of blood (average, 31.6 parasites $/ \mathrm{mL}$ ). Only two positive blood donors presented with more than 100 parasites per $\mathrm{mL}$ of blood (Figure 2).

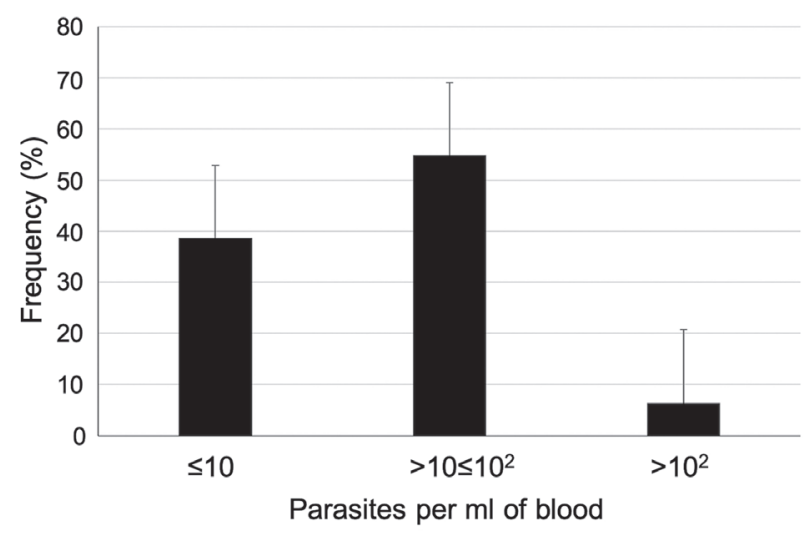

Figure 2 - Frequency of different parasite load ranges detected among the 31 positive blood donors for Leishmania spp. DNA detection by quantitative PCR.

When qPCR-positive samples were tested by the conventional PCR targeting $L$. infantum DNA, only one was positive.

\section{DISCUSSION}

In this study, we investigated the presence of Leishmania DNA in blood samples from donors coming spontaneously to a large blood bank in Northeastern Brazil. We found that $6.2 \%$ of the donors were carrying Leishmania DNA in their blood, and all of them were asymptomatic. Although the majority of positive blood donors resided in municipalities belonging to the Metropolitan region of Recife, the possibility that the infection had been acquired elsewhere cannot be ruled out.

Similar studies reporting the presence of anti-Leishmania antibodies or Leishmania DNA in asymptomatic blood donors have been carried out in Brazil ${ }^{10,14-21}$. Altogether, our results confirm that asymptomatic Leishmania infections are relatively frequent among blood donors living in endemic areas, since the screening of Leishmania DNA in blood banks in Brazil is still not routinely performed.

Different methods have been tested to prevent contamination of blood bags or even to destroy Leishmania parasites present in contaminated blood bags. For instance, filtration systems can remove several pathogens (e.g., cytomegalovirus, human T-lymphotropic virus, Orientia tsutsugamushi and Trypanosoma cruzi) from blood components $^{22}$. Leukodepletion filters used at the time of blood collection or bedside filters used after storage are reputed to be the best strategies to minimize the risk of blood transfusion transmission of Leishmania parasites ${ }^{7,22,23}$. The only issue related to the use of leukodepletion filters is the high costs, which may limit their large-scale use, particularly in low-income countries.

It is acknowledged that diagnosing asymptomatic Leishmania infections is not an easy task, due to the low parasite load and low to moderate humoral response in healthy, infected individuals ${ }^{8}$. In fact, we found a low parasite load among positive blood donors (mean of 31.6 parasites per $\mathrm{mL}$ of blood), highlighting the need of highly sensitive assays (e.g., qPCR) for detecting Leishmania infections in healthy individuals, as it is the case of blood donors. As a corollary, only one blood donor, with a parasite load of 201,01 parasites/ $\mathrm{mL}$ of blood, was positive when tested by conventional PCR, reinforcing the superiority of qPCR for detecting Leishmania DNA in asymptomatic carriers, especially when using blood samples, usually containing less parasite DNA as compared to other samples, such as bone marrow. Furthermore, the qPCR assay used herein is not specific for $L$. infantum, as it also detects $L$. braziliensis, another species endemic in Pernambuco ${ }^{24}$. The fact that only one qPCR-positive sample was positive in the L. infantum-specific conventional PCR could be related to the lower sensitivity of this assay or even to the presence of $L$. braziliensis. In fact, it is known that $L$. braziliensis DNA can be detected in blood samples of animals and humans ${ }^{25,26}$. The possibility that $L$. braziliensis could be transmitted via blood transfusion has been speculated ${ }^{19}$, but remains unproven.

It has been shown that individuals with higher parasite load are more infectious to phlebotomine sand fly vectors ${ }^{27}$. Nonetheless, the fact that blood donors examined herein presented a low parasite load and were asymptomatic does not necessarily mean that they are not infectious. A recent study suggested that not only VL patients, but also asymptomatic infected individuals could serve as a source of infection to phlebotomine sand fly vectors ${ }^{28}$.

It is acknowledged that VL is a disease of the poorest of the poor. The disease affects disproportionally poor people, 
living in rural areas or in suburbs, where the exposure to the vectors as well as the existence of predisposing factors (e.g., malnutrition and HIV coinfection) is frequent. In this study, no statistically significant differences were found in relation to gender, skin color, education level, income and place of residence. The absence of statistical differences may be partly explained by the low number of infected individuals, but may also indicates the lack of a well-defined epidemiological profile for Leishmania-infected blood donors ${ }^{29}$.

The determinant factors for progression from asymptomatic infection to symptomatic VL in humans are still poorly understood, but may be related to genetic background, nutritional status, underlying disease and/or coinfections. As such, we encourage public health authorities to elaborate specific guidelines for diagnosing and managing Leishmania infections in asymptomatic carriers in Brazil. These guidelines should also deal with blood donors diagnosed as infected during routine testing in blood banks, as well as blood recipients that received blood from infected donors. Finally, blood banks should exclude donors that are positive for Leishmania, as emphasized elsewhere ${ }^{22}$.

In conclusion, we report herein the finding of asymptomatic Leishmania carriers in $6.2 \%$ of asymptomatic blood donors in a large blood bank in Northeastern Brazil. This finding reinforces the urgent need for elaborating specific blood bank guidelines to allow the early detection of asymptomatic Leishmania carriers who show up to donate blood before their blood products are transfused to uninfected individuals. This would ultimately benefit both, asymptomatic Leishmania carriers themselves, but especially blood recipients by reducing the risk of $\mathrm{VL}$ in these individuals.

\section{ACKNOWLEDGMENTS}

We would like to thank the staff of the Fundação de Hematologia e Hemoterapia de Pernambuco (Hemope) for their assistance with sample collection and to the Fundação de Amparo a Ciência e Tecnologia do Estado de Pernambuco (FACEPE, grant No APQ 1620-4.01/15). FCSS received a $\mathrm{PhD}$ scholarship from Conselho Nacional de Desenvolvimento Científico e Tecnológico (CNPq). FDT is the recipient of a research productivity scholarship from CNPq (grant $\mathrm{N}^{\circ} 313118 / 2018-3$ ). Thanks also to Lucas C. de Sousa-Paula (Aggeu Magalhães Institute, Fiocruz, Brazil) for elaboration of Figure 1.

\section{REFERENCES}

1. Alvar J, Vélez ID, Bern C, Herrero M, Desjeux P, Cano J, et al. Leishmaniasis worldwide and global estimates of its incidence. PLoS One. 2012;7:e35671.
2. Nylén S, Gautam S. Immunological perspectives of leishmaniasis J Glob Infect Dis. 2010;2:135-46.

3. Bañuls AL, Bastien P, Pomares C, Arevalo J, Fisa R, Hide M. Clinical pleiomorphism in human leishmaniases, with special mention of asymptomatic infection. Clin Microbiol Infect. 2011;17:1451-61.

4. Stauch A, Sarkar RR, Picado A, Ostyn B, Sundar S, Rijal S, et al. Visceral leishmaniasis in the Indian subcontinent: modelling epidemiology and control. PLoS Negl Trop Dis. 2011; 5:e1405.

5. Dantas-Torres F, Miró G, Baneth G, Bourdeau P, Breitschwerdt E, Capelli G, et al. Canine leishmaniasis control in the context of one health. Emerg Infect Dis. 2019;25:1-4.

6. Maroli M, Feliciangeli MD, Bichaud L, Charrel RN, Gradoni L. Phlebotomine sandflies and the spreading of leishmaniases and other diseases of public health concern. Med Vet Entomol. 2013;27:123-47.

7. Asfaram S, Fakhar M, Soosaraei M, Hosseini Teshnizi S, Mardani A, Banimostafavi ES, et al. Global status of visceral leishmanial infection among blood donors: a systematic review and meta-analysis. Transfus Apher Sci. 2017;56:748-54.

8. Michel G, Pomares C, Ferrua B, Marty P. Importance of worldwide asymptomatic carriers of Leishmania infantum (L. chagasi) in human. Acta Trop. 2011;119:69-75.

9. Brasil. Ministério da Saúde. Agencia Nacional de Vigilância Sanitária. Manual técnico para investigação da transmissão de doenças pelo sangue. Brasília: Ministério da Saúde; 2004.

10. Ferreira-Silva MM, Teixeira LA, Tibúrcio MS, Pereira GA, Rodrigues V, Palis M, et al. Socio-epidemiological characterization of blood donors with asymptomatic Leishmania infantum infection from three Brazilian endemic regions and analysis of the transfusional transmission risk of visceral leishmaniasis. Transfus Med. 2018;28:433-9.

11. Francino O, Altet L, Sánchez-Robert E, Rodriguez A, SolanoGallego L, Alberola J, et al. Advantages of real-time PCR assay for diagnosis and monitoring of canine leishmaniasis. Vet Parasitol. 2006;137:214-21.

12. Dantas-Torres F, Sales KG, Silva LG, Otranto D, Figueredo LA. Leishmania-FAST15: a rapid, sensitive and low-cost realtime PCR assay for the detection of Leishmania infantum and Leishmania braziliensis kinetoplast DNA in canine blood samples. Mol Cell Probes. 2017;31:65-9.

13. Gualda KP, Marcussi LM, Neitzke-Abreu HC, Aristides SM, Lonardoni MV, Cardoso RF, et al. New primers for detection of Leishmania infantum using polymerase chain reaction. Rev Inst Med Trop Sao Paulo. 2015;57:377-83.

14. Luz KG, Silva VO, Gomes EM, Machado FC, Araujo MA, Fonseca HE, et al. Prevalence of anti-Leishmania donovani antibody among Brazilian blood donors and multiply transfused hemodialysis patients. Am J Trop Med Hyg. 1997;57:168-71. 
15. Otero AC, Silva VO, Luz KG, Palatnik M, Pirmez C, Fernandes O, et al. Short report: occurrence of Leishmania donovani DNA in donated blood from seroreactive Brazilian blood donors. Am J Trop Med Hyg. 2000;62:128-31.

16. França AO, Castro VL, Lima Jr MS, Pontes ER, Dorval ME. Anti-Leishmania antibodies in blood donors from the midwest region of Brazil. Transfus Apher Sci. 2013;49:627-30.

17. Clemente WT, Rabello A, Faria LC, Peruhype-Magalhães V, Gomes LI, Silva TA, et al. High prevalence of asymptomatic Leishmania spp. infection among liver transplant recipients and donors from an endemic area of Brazil. Am J Transplant. 2014;14:96-101.

18. Fukutani KF, Figueiredo V, Celes FS, Cristal JR, Barral A, BarralNetto M, et al. Serological survey of Leishmania infection in blood donors in Salvador, northeastern Brazil. BMC Infect Dis. 2014;14:422.

19. Braga LS, Navasconi TR, Leatte EP, Skraba CM, Silveira TG, Ribas-Silva RC. Presence of anti-Leishmania (Viannia) braziliensis antibodies in blood donors in the West-Central region of the State of Paraná, Brazil. Rev Soc Bras Med Trop. 2015;48:622-5

20. Monteiro DC, Sousa AQ, Lima DM, Fontes RM, Praciano CC, Frutuoso MS, et al. Leishmania infantum infection in blood donors, northeastern Brazil. Emerg Infect Dis. 2016;22:739-40.

21. França AO, Pompilio MA, Pontes ER, Oliveira MP, Pereira LO, Lima RB, et al. Leishmania infection in blood donors: a new challenge in leishmaniasis transmission? PLoS One. 2018;13:e0198199.

22. Mansueto P, Seidita A, Vitale G, Cascio A. Transfusion transmitted leishmaniasis. What to do with blood donors from endemic areas? Travel Med Infect Dis. 2014;12:617-27.
23. Jimenez-Marco T, Fisa R, Girona-Llobera E, Cancino-Faure B, Tomás-Pérez M, Berenguer D, et al. Transfusion-transmitted leishmaniasis: a practical review. Transfusion. 2016;56 Suppl 1:S45-51.

24. Brito ME, Andrade MS, Dantas-Torres F, Rodrigues EH, Cavalcanti MP, Almeida AM, et al. Cutaneous leishmaniasis in northeastern Brazil: a critical appraisal of studies conducted in State of Pernambuco. Rev Soc Bras Med Trop. 2012;45:425-9.

25. Dantas-Torres F, Paiva-Cavalcanti M, Figueredo LA, Melo MF, Silva FJ, Silva AL, et al. Cutaneous and visceral leishmaniasis in dogs from a rural community in northeastern Brazil. Vet Parasitol. 2010;170:313-7.

26. Martins L, Alexandrino A, Guimarães G. Detection of Leishmania braziliensis DNA in American tegumentary leishmaniasis patients. Rev Saude Publica. 2010;44:571-4.

27. Courtenay O, Peters NC, Rogers ME, Bern C. Combining epidemiology with basic biology of sand flies, parasites, and hosts to inform leishmaniasis transmission dynamics and control. PLoS Pathog. 2017;13:e1006571.

28. Ferreira GR, Ribeiro JC, Meneses Filho A, Pereira TJ, Parente DM, Pereira HF, et al. Human competence to transmit Leishmania infantum to Lutzomyia longipalpis and the influence of human immunodeficiency virus infection. Am J Trop Med Hyg. 2018;98:126-33.

29. Alvar J, Yactayo S, Bern C. Leishmaniasis and poverty. Trends Parasitol. 2006;22:552-7.

30. OpenStreetMap. [cited 2020 Aug 9]. Available from: https://www. openstreetmap.org 